\title{
Minimal effect of honey beehive fences on native bee diversity and abundance at the farm scale during the dry season in southern Kenya
}

\author{
L. E. King ${ }^{1,2}$, E. SEREM ${ }^{1}$, L. Russo ${ }^{3,4}$ \\ ${ }^{1}$ The Elephants and Bees Project, Save the Elephants, Nairobi, Kenya \\ ${ }^{2}$ Department of Zoology, University of Oxford, Oxford, UK \\ ${ }^{3}$ Botany Department, Trinity College Dublin, Dublin 2, Ireland \\ ${ }^{4}$ Biology Department, the Pennsylvania State University, University Park, PA, USA
}

Received 5 July 2018 - Revised 3 September 2018 - Accepted 4 October 2018

\begin{abstract}
Beehive fences are an effective solution to resolve conflicts between humans and crop-raiding elephants in Kenya. They produce win-win scenarios; elephants are protected from aggression from humans as they are deterred from crop raiding, while farmers benefit from crop protection, pollination, and valuable products from maintaining honeybee hives. However, artificially increasing the density of these super-generalist pollinators in the landscape may impact wild bee species as honeybees may out-compete them for floral resources. We studied bee communities in Sagalla, Kenya, where beehive fences have been implemented for crop protection for many years. Despite the long-term presence of the beehive fences, honeybee densities were low when the study was conducted because of a severe drought and did not differ between beehive and control fences in our collections. When we compared farms with and without beehive fences, we found little difference in the abundance, species richness, and community composition of the resident wild bee communities. This suggests either (a) beehive fences have little permanent impact on wild bee communities, or (b) wild bee communities recover quickly when honeybee densities are low.
\end{abstract}

Agroecosystems / Bee communities / Beehive fences / Honeybees / Human-wildlife conflict

\section{INTRODUCTION}

Human-wildlife conflict exists where humans and wildlife are competing for limited resources (Dickman 2010; Nyhus 2016). The intensity of this problem is increasing globally as the human population density rises, especially in developing countries (Manfredo 2015). In Kenya, increasing population densities of both African elephants (Loxodonta africana) and humans have led to an intensification of conflicts between humans

Electronic supplementary material The online version of this article (https://doi.org/10.1007/s13592-018-0608-9) contains supplementary material, which is available to authorized users.

Corresponding author: L. Russo, russola@tcd.ie Manuscript Editor: Alexandra Klein and crop-raiding elephants (Sitati and Walpole 2006; King et al. 2009, 2011, 2017). Elephants are perceived to be among the most destructive of the crop-raiding animals (Mwakatobe et al. 2014), and crop raiding by elephants not only threatens the livelihood of subsistence farmers, but breeds ill will between farmers and elephants (Graham and Ochieng 2017). It may also cause farmers to shelter poachers, thereby threatening the welfare of the elephants and undermining conservation efforts (Pittiglio et al. 2014; Redpath et al. 2013).

Many options have been proposed to deter crop-raiding elephants from farms, and in some places the government has subsidized large stretches of electric fences that are relatively effective elephant deterrents (Kioko et al. 2008; Okello and D'Amour 2008). However, large- 
scale implementation of electric fences is neither practical nor affordable for most farmers, and it interferes with the natural migration of elephants and other animals, as well as the movement of humans (Evans and Adams 2016). In light of this, a multitude of more affordable options are often implemented by rural farmers (Graham and Ochieng 2017), often including defense of the farm by the farmer, which may place the farmer in harm's way (King 2010). Many of the alternative affordable deterrents, including chili rope fences, chili smoke briquettes (Osborn 2002; Karidozo and Osborn 2015), cow bells, noise makers, and watchtowers, have variable impacts on reducing elephant crop raiding (Graham and Ochieng 2017) and habituation and ongoing maintenance costs can be detrimental to the upkeep of the method (Hoare 2012).

The Elephants and Bees Project run by the research organization Save the Elephants in Kenya utilizes "beehive fences" to deter elephants that would otherwise raid crops on small farms (www. elephantsandbees.com). Beehive fences consist of beehives strung every $10 \mathrm{~m}$ on interconnecting wires around the perimeter of a farm. Elephants that attempt to cross the fence disturb the bees and are scared away by the buzzing and stinging insects; the design has been shown to be effective in reducing elephant raiding by African elephants in several locations in Kenya (King et al. 2009; King et al. 2011; King et al. 2017) and Gabon (Ngama et al. 2016) and by Asian elephants (Elephas maximus ) in India (Nair and Jayson 2016).Beehive fences have several advantages: they are sustainable, benefit the farmer by producing valuable products such as honey and wax, and produce pollinators for the crops they are protecting (Kasina et al. 2009a). They are economically viable and manageable by the farmers themselves, especially because many rural Kenyan farmers have experience with beekeeping (King 2010). Honeybees, along with a variety of native bees, are important pollinators for Kenyan crops (Kasina et al. 2009b).

One concern with widespread adoption of the beehive fences is that they may locally increase the density of honeybees to the extent that they outcompete other ecologically important bee species (Martins 2004). Honeybees (Apis mellifera
L.) are native to Kenya, but they are also strong competitors in the floral resource market (Thomson 2004) even in their native range (Goulson and Sparrow 2009; Herbertsson et al. 2016). In places where the honeybee is considered invasive, there is mixed evidence that it may or may not compete with native wild bees for pollen and nectar (Roubik and Wolda 2001; Paini 2004; Paini and Roberts 2005; Badano and Vergara 2011). Honeybees rely on cavities for nesting and, as deforestation progresses in Africa, suitable nesting sites may become less available, especially in agricultural regions (Dietemann et al. 2009). On the other hand, agricultural areas can provide valuable resources to a diversity of wild bees (Russo et al. 2015). Sub-Saharan Africa has a large number of bee species (Eardley et al. 2009; Gikungu et al. 2011) and conserving these wild pollinators may be essential for sustainable crop pollination (Njoroge et al. 2010, Gemmill-Herren et al. 2014). Because nesting sites are thought to be the limiting resource on honeybee density in Kenya, our question was: does widespread implementation of beehive fences have negative impacts on wild bee fauna in agricultural areas?

To answer this question, we compared wild bee communities in Kenyan farms with and without beehive fences in Sagalla, an agricultural area of southern Kenya. Over the course of 3 weeks during the dry season of 2017, we used passive and active bee collection methods to determine whether there was a difference in the wild bee community in response to the implementation of beehive fences.

\section{MATERIAL AND METHODS}

\subsection{Site selection}

The Elephants and Bees Project of Save the Elephants was initiated in the Sagalla region of southern Kenya in 2009. This agricultural community is vulnerable to human-elephant conflict because of its location adjacent to Tsavo National Parks. The beehive fences have been shown to protect crops by deterring $80 \%$ of approaching elephants from raiding the farms (King et al. 2017), and they continue to be monitored and tested for efficacy in this region. 
In the village of Mwakoma in Sagalla, there are 13 farms with beehive fences. From these 13, we selected the five farms with the highest beehive occupation (where occupation is defined as the number of occupied hives in the length of fence), and paired them with similarly sized farms without beehive fences (controls) for our study. The farms varied in size from 0.011 to $0.043 \mathrm{~km}^{2}$, but there was no significant difference in size between control and beehive fence farms $(P=0.20)$ and within a pair; farm size differed by a maximum of $12 \%$ (Figure $\mathrm{S} 1$ ). The farms each grew a mix or subset of maize, cow peas, green grams, and forage crops for cattle and goats.

Each pair (one beehive fence farm and one control farm) was separated by no more than $500 \mathrm{~m}$ and no less than $250 \mathrm{~m}$. We chose adjacent farms to be pairs so that the background environment would be similar between paired farms. Honeybees were also occasionally observed within the landscape living in natural nesting habitat at low densities. We did not control these unmanaged bees, but rather wished to determine whether locally increasing honeybee density with artificial hives had a significant impact on other wild bee species.

Due to poor rains and a long dry season in 2016, there was low hive occupation across the farming site during our study; however, we chose the five farms with the highest beehive occupation for this survey. These five farms contained 63 beehives between them with 16 hives $(25 \%)$ occupied by honeybees. Although hive occupation was low for the fences, these 16 occupied hives were likely to contain between $10,000-50,000$ individual bees per hive (Paterson 2016; Locke and Fries 2011) representing an potential extra 160,000 to 800,000 honeybees introduced to the system by the construction of the beehive fence network.

\subsection{Data collection}

To understand how the wild bee community responded to the increased density of honeybees on farms with beehive fences, we conducted two different kinds of bee surveys: a passive pan trap collection and active sweep net sampling. We sampled the ten farms during the dry season
(January-February) of 2017. Paired farms were always sampled together.

At each of these farms, we established a 50-m transect. In beehive fence farms, this transect started at the edge of the beehive fence and continued $50 \mathrm{~m}$ perpendicular to the fence away from the farm. In farms without beehive fences, we established each transect on the edge of the crop field and it continued $50 \mathrm{~m}$ away from the crop field. Starting at $0 \mathrm{~m}$ on this transect and then at every $10 \mathrm{~m}$, we put three pan traps (yellow, blue, and white) filled with soapy water (Roulston et al. 2007). The pan traps were left for $24 \mathrm{~h}$ once a week for the 3 weeks of our sampling (Figure 1).

We also conducted six 30-min sweep net surveys (four in the morning and two in the afternoon at each farm) at each of the farms. With two people sampling during each sweep net survey, this resulted in $60 \mathrm{~h}$ of active collecting bees on flowers. During these net surveys, we recorded the identity of the plants on which we collected individual bee species. We identified most plants to species level, but some were only identifiable to genus or morphospecies. Using these visitation data, we were able to construct networks of interactions between bees and plants (Russo et al. 2013). These networks are bipartite because they have two types of nodes (plants and bees); within bipartite networks, plant species cannot interact with other plant species, and bee species cannot interact with other bee species. Thus, plants can only interact with bees and vice versa. Bipartite networks are a natural model for plant-pollinator interactions and allow analyses of changes in interactions at the community level (Memmott 1999). Network models are also used to monitor the responses of a community to perturbation, including the introduction of new species (Lopezaraiza-Mikel et al. 2007; Russo et al. 2014).

We identified all the collected bee specimens to the morphospecies level. Photographs of the morphospecies were checked and corrected by Connal Eardley (Agricultural Research Council, South Africa). The specimens are stored at the Nairobi National Museum in Nairobi, Kenya. The photographic database of the morphospecies is publicly available online at https://tinyurl.com/kofa8e4. 

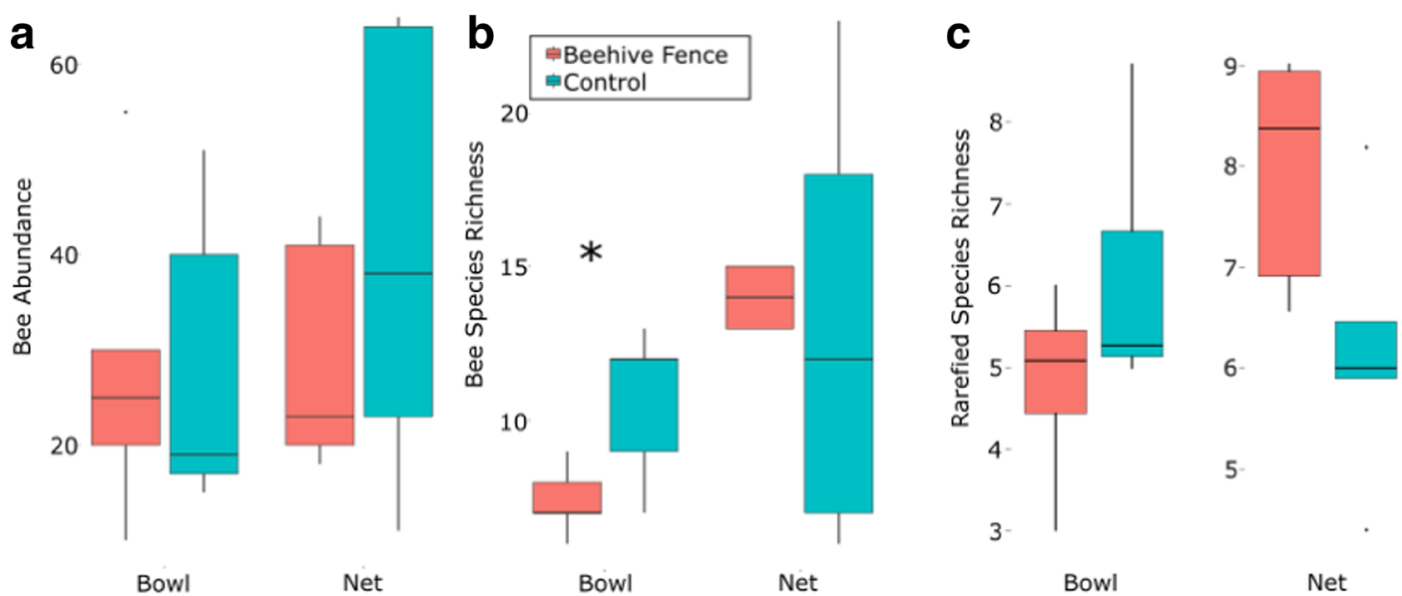

Figure 1. Bee abundance (a) species richness (b) and rarefied species richness (c) in beehive fence farms (red) and control farms (blue) using pan trap or net-collection methods. The asterisk (*) demarcates the significant difference between species richness detected by the pan-trap collections. However, when the samples are rarefied to correct for the relative abundances of different species, there is no significant difference in the species richness in beehive fence and control farms.

\subsection{Data analysis}

To determine whether the presence of the beehive fences had a significant impact on the wild bee community on beehive fence farms relative to control farms, we conducted several complementary statistical tests.

First, we established whether honeybee density was higher on beehive fence farms relative to the controls using paired $t$ tests (five pairs of beehive fence and control farms). We pooled samples across the study period for these comparisons. To test whether honeybee density differed between control and beehive fence farms while including all sample dates, we also used a GLMM with honeybee abundance as a response variable, treatment as a fixed effect, and sample date and site as random effects.

Because we hypothesized honeybee density would decrease as we sampled farther from the fence along the 50-m transect, we used the pan trap data to test whether there was a significant correlation between the bee community structure in beehive fence farms and control farms by using a Mantel test to determine whether there was a correlation between the Jaccard distance matrices for the samples collected along the 50-m transect, pooled over time. We then visually represented these communities using ordination methods (NMDS).

Next, we compared the species richness and abundance of wild bees on farms with and without beehive fences in pan trap and net collections using paired $t$ tests. For these tests, samples were pooled across the study period. We evaluated pan trap and net collections separately before pooling the specimens because pan traps and sweep nets can collect very different bee communities (Roulston et al. 2007). We also used a rarefaction analysis to correct for the relative abundances of different species by subsampling each site according to the site with the lowest abundance of specimens. We then used generalized linear mixed effects models (GLMMs) to determine whether the presence of a beehive fence (fixed effect) affected pooled (net and pan trap-collected specimens) bee abundance and species richness, with farm site and date of sample as random effects.

Finally, we constructed bee-plant networks from the net-collected bees. We compared structural properties of bee-plant networks on beehive fence farms to that of control farms, including the average degree, connectance, nestedness, number of compartments, and average number of effective partners (Table I). We compared these aspects of network structure because previous work has 
Table I. Ecological interpretation of network properties measured in this paper

\begin{tabular}{ll}
\hline Network properties & Ecological Interpretation \\
\hline $\begin{array}{l}\text { Average degree } \\
\text { Connectance }\end{array}$ & $\begin{array}{c}\text { The average degree is the average number of species a given bee or plant interacts with. } \\
\text { The connectance is the total number of interactions between species in the network divided by the } \\
\text { number of possible interactions (number of plant species multiplied by number of bee species). } \\
\begin{array}{l}\text { Number of } \\
\text { compartments }\end{array} \\
\text { Nestedness }\end{array}$ \\
$\begin{array}{l}\text { Nestedness quantifies how ordered a real network is relative to a simulated perfectly ordered } \\
\text { network by quantifying to which degree interaction partners of specialized species are subsets of } \\
\text { the partners of more generalized species. }\end{array}$ \\
$\begin{array}{l}\text { The number of effective partners of each species is a measure that explains how many partners each } \\
\text { species would interact with if there were no difference in the background abundance of species. } \\
\text { In quantitative networks such as these, background abundance is measured by the number and } \\
\text { frequency of interactions of each species. }\end{array}$ \\
\hline
\end{tabular}

shown that super-generalist novel species may change these structural characters in predictable ways, and that network methods can detect community level changes that traditional methods may not detect (Russo et al. 2014).

\section{RESULTS}

Over the course of the study, we collected 627 bee specimens representing 63 morphospecies. The majority of the specimens were from the families Apidae (53\%), Halictidae (38\%), and Megachilidae (8\%) with only one specimen from Andrenidae (Meliturgula minima Friese), similar to other studies of farmland bee diversity in Kenya (e.g., Mwangi et al. 2012).

There was no significant difference between honeybee densities collected by net between beehive fence farms and control farms when using a $t$ test $(P=0.3, t$ stat $=0.57)$ and GLMM $(t$ stat $=$ $0.52, P=0.60)$. Because only one honeybee was collected in a pan trap during the study, we were not able to test the effect of distance from the beehive fence on honeybee densities. This may be due to the fact that some bee species, including honeybees, avoid pan traps (Roulston et al. 2007), though other studies collected honeybees in pan traps in high densities (Hall 2018). This may be related to pan trap height (Tuell and Isaacs 2009).

There was a significantly greater variety of bee species (higher species richness) in pan traps alone in control farms relative to pan traps beehive fence farms $(P=0.03, t$ stat $=2.58)$, but there was no significant difference in the species richness of beehive fence and control farms when we rarefied the samples $(P>0.05)$. The presence of a beehive fence did not alter bee abundance (total number of specimens, $t$ stat $0.48, P=0.63$ ) or species richness (total number of bee species, $t$ stat $=0.23$, $P=0.82$ ) when we pooled all collected specimens and controlled for site level variation and sample dates in the generalized linear mixed effects model.

There was no significant relationship between the distance matrices of beehive fence farms and control farms along the $50-\mathrm{m}$ pan trap transects $(P=0.98$, Mantel $r$ stat $=-0.71)$. However, a visual representation of these communities using NMDS ordination methods shows a large degree of overlap (Figure 2). In general, the most common bee morphospecies were shared between the two farm types (Braunsapis, Macrogalea, Lasioglossum morph 1, Tetralonia morph 1), while less common morphospecies tended to be found in one farm type only (e.g., Pseudapis morph 1, Lasioglossum morphs 3 and 4, Lipotriches morph 3, Tetralonia morph 2), probably because they were collected only rarely. In other words, these uncommon species drove observed differences in the distance matrices, but the number of uncommon species did not differ between the farm types.

In the network analysis, the average degree, nestedness, and number of compartments did not 

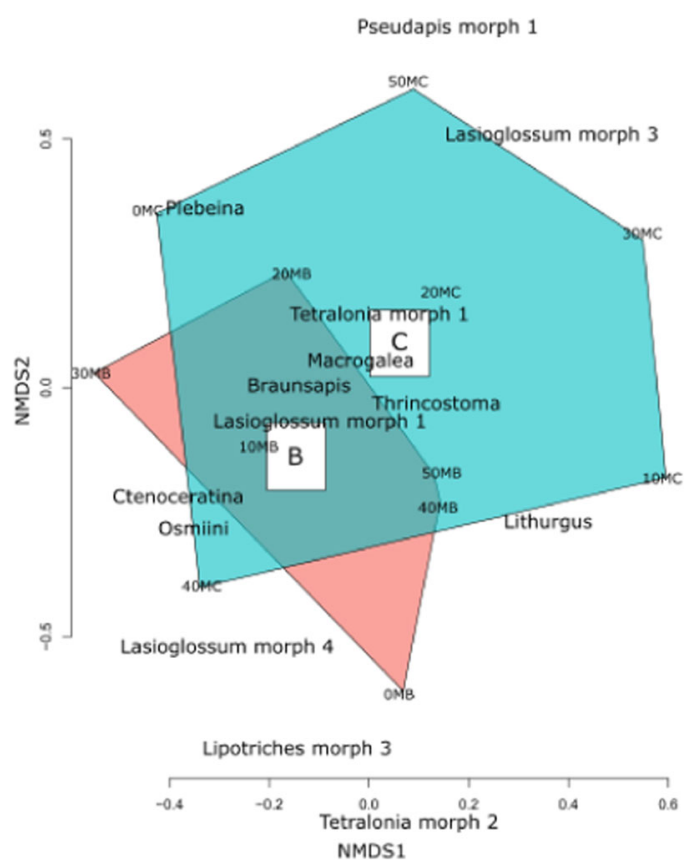

Figure 2. A non-metric dimensional-scaling (NMDS) plot of the community structure along $50-\mathrm{m}$ transects in beehive fence $(\mathrm{B}, \mathrm{red})$ and control $(\mathrm{C}$, blue) farms. The different positions on the transects are demarcated by the distance and treatment (e.g., 0 m B). Selected influential morphospecies are shown on the plot.

differ between beehive fence farms and control farms $(P>0.05$, Table II). The connectance of beehive fence farms was significantly lower than control farms $(P=0.007, t$ stat $=-4.12)$; this is likely due to the fact that bees on beehive fence farms interacted with significantly more plant species $(P=0.01, t$ stat $=3.47)$ as beehive fence farms had higher plant species richness than control farms, while the net-collected bee species richness remained constant (Figure 3, Table II). Furthermore, species in beehive fence farms had a slightly lower number of effective partners $(P=$ $0.04, t$ stat $=-2.38)$. This is probably also due to the higher plant species richness in surveyed beehive fence farms.

\section{DISCUSSION}

Honeybees are super generalists, and may compete with wild bees for floral resources (Roubik and Wolda 2001, Paini 2004, Martins 2004, Paini and Roberts 2005, Badano and Vergara 2011, Shavit et al. 2009). In places where they have been deliberately or accidentally introduced, there is some concern about their impacts on wild bees (Moritz et al. 2005). Honeybees are native to Kenya, but their density is limited by the availability of nesting cavities, especially in agricultural areas. Because of this, the installation of the beehive fences may have the effect of artificially increasing the density of honeybee workers in the local landscape. Because agricultural areas can also provide resources for a large diversity of wild bees (Russo et al. 2015; Kasina et al. 2009b), introducing beehive fences may have the unintended consequence of increasing competition between honeybees and wild bees (Martins 2004).

Our study may suggest that the installation of beehive fences in an agricultural region of southern Kenya either has little permanent effect on the composition and structure of wild bee communities relative to neighboring farms or that they can recover quickly when honeybee densities are low. Though there was a significantly lower bee species richness in pan trap-collected bees in beehive fence farms, this effect was not reflected in the net-collected bees and was not significant when the samples were rarefied to correct for differences in species abundances. Similarly, the abundance of wild bees did not differ in either pan trap or net-collected bee specimens. Though the distance matrices of these two farm types along the 50-m transect did not correlate, our ordination plot showed substantial overlap in the bee community types, with the differences driven by uncommon bee morphospecies (Pseudapis morph 1, Lasioglossum morphs 3 and 4, Lipotriches morph 3, Tetralonia morph 2). Similarly, the average degree, number of compartments, and nestedness of the bee-plant network structure did not differ between beehive fence farms and control farms (Table II).

There was a significantly lower connectance and average number of effective partners in beehive fence farms (Table II); this was largely driven by a higher plant species richness in these farms. Increasing the plant species richness without changing the abundance or species richness of the bees will necessarily result in lower connectance and effective partners. The cause of 
Table II. Averages of network properties of beehive fence farms relative to control farms \pm their standard error $(n=$ 5). There are more plant species in beehive fence farm networks, while the number of bee species remains the same, resulting in a significantly lower connectance and number of effective partners

\begin{tabular}{|c|c|c|c|c|c|c|c|}
\hline & $\begin{array}{l}\text { Plant } \\
\text { species }\end{array}$ & $\begin{array}{l}\text { Bee } \\
\text { species }\end{array}$ & $\begin{array}{l}\text { Average } \\
\text { degree }\end{array}$ & Connectance & Nestedness & Compartments & $\begin{array}{l}\text { Effective } \\
\text { partners }\end{array}$ \\
\hline Control & $4.2+0.73$ & $13.2+3.25$ & $2.17+0.25$ & $0.76+0.1$ & $12.61+5.62$ & $2.8+0.58$ & $1.57+0.28$ \\
\hline $\begin{array}{l}\text { Beehive } \\
\text { fence }\end{array}$ & $6.8+0.37$ & $14+0.45$ & $1.95+0.29$ & $0.66+0.07$ & $11.48+4.18$ & $3.2+1.12$ & $1.52+0.22$ \\
\hline$P$ value & 0.01 & 0.4 & 0.08 & 0.01 & 0.11 & 0.3 & 0.04 \\
\hline$t$ stat & 3.47 & 0.28 & -1.73 & -4.12 & -1.46 & 0.56 & -2.38 \\
\hline
\end{tabular}
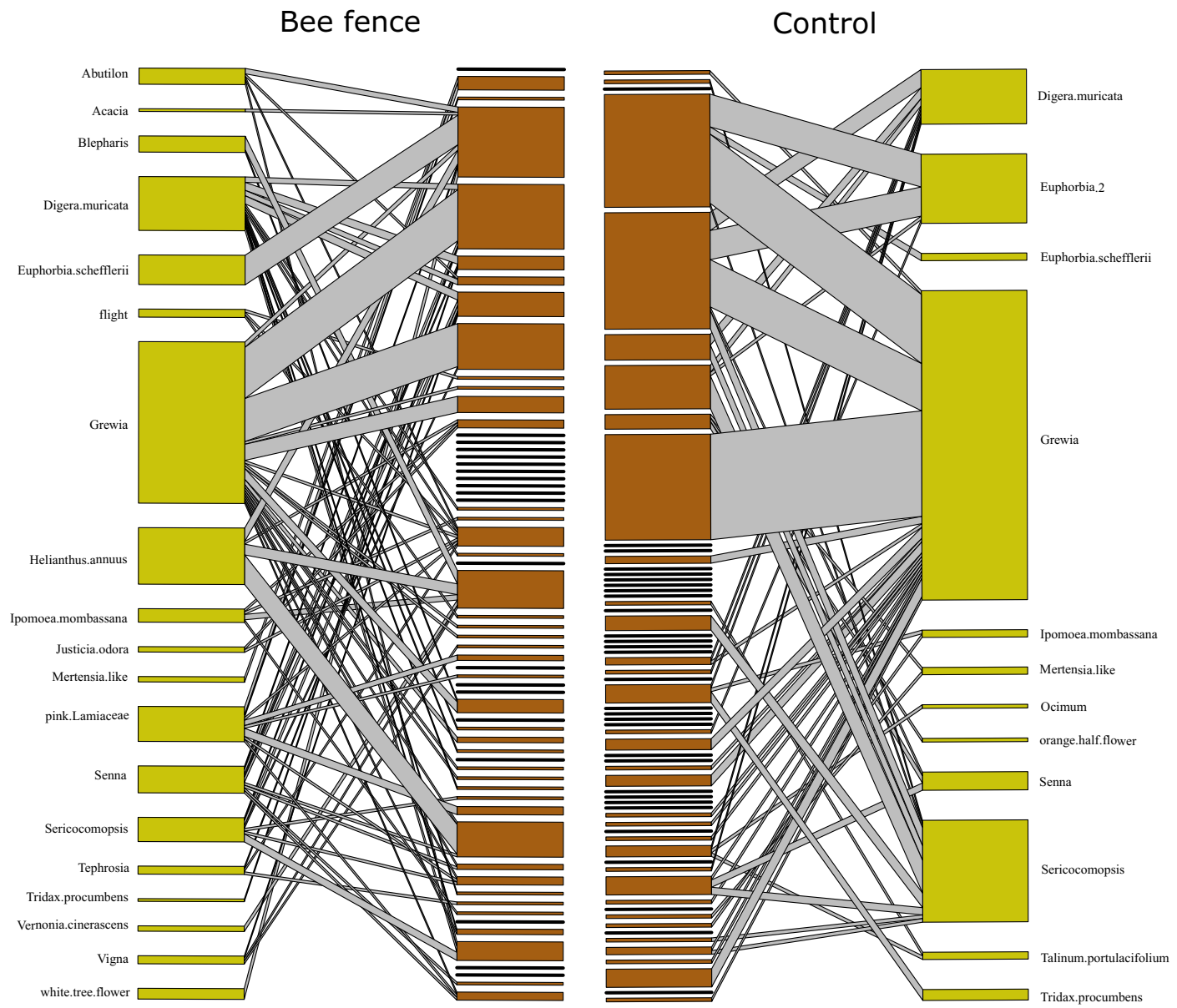

Figure 3. The summed network interactions of farms with (left) and without (right) beehive fences. The gold boxes represent plant species and morphospecies on which bees were collected, while the orange boxes represent the bee species and morphospecies collected (see photographic database: https://tinyurl.com/kofa8e4). The lines connecting the boxes represent interactions, and the thickness of the lines represents the frequency of the interaction. 
this higher plant species richness is unknown, but could be caused by differences in land management behavior of the five beehive fence farmers relative to control farmers or potentially protection from elephant foraging. Beehive fence farmers have been encouraged by the Elephants and Bees Project not to cut flowering plants and to leave them as fodder for their bee colonies and this management influence could be responsible for greater plant diversity over the 5 years since the beehive fences were introduced.

We conducted our study during a dry season (January-February 2017) when the hive occupation of the beehive fences was very low. However, even low occupation across the potential number of hives available could still have resulted in hundreds of thousands of worker bees being introduced to the system as each beehive can be home to as many as 10,000 to 50,000 honeybees (Paterson 2016). Flowering was also lower than in most years because of a drought (only a third of the rain expected fell in the prior wet season) so competition for flower resources could have been higher than expected. When floral resources are scarce, oligolectic wild bees may be outcompeted by honeybees (Martins 2004). Consequently, as the beehive fences have been present on the landscape since 2009, the absence of an observable difference in wild bee species, even during the dry season, suggests that there are few permanent impacts on the structure of the wild bee community through the introduction of beehive fences. Future research should address the structure of the wild bee community when the beehive occupation (and honeybee density) is at its highest. This scenario may result in the largest potential competitive impacts on wild bees.

Honeybees are capable of foraging for long distances, more than $7 \mathrm{~km}$ away from the hive (Couvillon et al. 2014). However, the density of honeybees decreases as the distance away from the hive increases (Hagler et al. 2011), and honeybees will not forage farther away from the hive if there are sufficient floral resources near the hive (Couvillon et al. 2014).Though the control farms were within the possible foraging range of the honeybees in the beehives, flowering plant diversity was higher in beehive fence farms and we still expected honeybee density to be highest on beehive fence farms. Nonetheless, we did not detect significant differences in honeybee densities between beehive and control farms during our survey, possibly because of low hive occupation.

We were comparing farms in an area where beehive fences have long been established, but the ideal way to test the question of whether beehive fences alter the wild bee community would be to evaluate the wild bee community before and after the introduction of beehive fences. Furthermore, the short duration of this study means that there is a large proportion of bee species that were likely active outside of the study period. A before-andafter experiment with year-long collections over multiple years would be necessary to be fully confident that there is no impact of beehive fences on the wild bee community. Thus, it is possible that the temporal or spatial scale of our study was too small to detect a difference in bee communities.

Nonetheless, the absence of large differences between wild bee communities between beehive fence farms and control farms is encouraging, though not conclusive, for those wishing to use this management strategy to reduce humanelephant conflicts. Our data could suggest that there are no significant permanent effects of the beehive fences on these wild bee communities during the foraging constraints of a dry season, at least at the scale to which they have been deployed as shown in this study. It is also possible that the wild bee communities simply recover when honeybee densities are low. In this sense, this study demonstrates the resilience of communities of bees to perturbations, such as increasing the density of super-generalist competitors.

\section{ACKNOWLEDGEMENTS}

We thank the farmers who allowed us to collect bees on their land, without whom this study would not have been possible: P. Mwakio, F. Malandi, B. Njaka, A. Mwambanga, J. Kakongo, N. Wabongo, H. Njaka, K.K. Ngelo, and C. Wauda. We also thank the researchers and staff at the Save the Elephants' Elephants and Bees Research Center, who were essential assistants on the project: E. Mwambingu, G. Mugo, E. Ruto, G. Troup, T. Tindall, S. Weinmann, H. Nzumu, and K. Zakeer. We also thank the taxonomists who gave us assistance during this project, including C. Eardley, L. Packer, D. Martins, and M. Gikungu. 


\section{AUTHOR CONTRIBUTIONS}

L.K. conceived of and established the beehive fences and collaborated with farmers. L.K. and L.R. conceived of the study. L.R. and E.S. collected the data. L.R. analyzed the data and wrote the first draft. All authors read and contributed significantly to revisions.Funding information

LR was funded on NSF grant \#DMS-1313115 and a Marie Curie Independent Fellowship FOMN 705287.

\section{COMPLIANCE WITH ETHICAL STANDARDS}

Conflict of interest The authors declare that they have no conflict of interest.

Effet minime des clôtures autour des ruches sur la diversité et l'abondance des abeilles indigènes de terres agricoles pendant la saison sèche dans le sud du Kenya

Agroécosystèmes / communautés d'abeilles /clôtures de ruche / abeilles / conflit homme-vie sauvage

Der Minimaleffekt der Umzäunung um Honigbienenvölker auf die Diversität und Abundanz von Wildbienen in landwirtschaftlich genutzten Flächen während der Trockenzeit im südlichen Kenia

Agroekosysteme/Bienengemeinschaften/Umzäunung von Bienenvölkern/Mensch-Umweltkonflikt

\section{REFERENCES}

Badano, E., Vergara, C. (2011) Potential negative effects of exotic honey bees on the diversity of native pollinators and yield of highland coffee plantations. Agric. For. Entomol., uce the fecundity of an Australian native bee (H, 365-372.

Couvillon, M.J., Schürch, R., Ratnieks, F.L.W. (2014) Dancing bees communicate a foraging preference for rural lands in high-level agri-environment schemes. Curr. Biol. 24 (11), 1212-1215.

Dickman, A.J. (2010) Complexities of conflict: the importance of considering social factors for effectively resolving human-wildlife conflict. Anim. Conserv., 13, $458-466$.
Dietemann, V., Pirk, C.W.W., Crewe, R. (2009) Is there a need for conservation of honeybees in Africa?. Apidologie, 40, 285-295.

Eardley, C.D., Gikungu, M. and Schwarz, M.P. (2009) Bee conservation in Sub-Saharan Africa and Madagascar: diversity, status and threats. Apidologie, 40 (3), 355366.

Evans, L.A., Adams, W.M. (2016) Fencing elephants: The hidden politics of wildlife fencing in Laikipia, Kenya. Land Use Policy, 51, 215-228.

Gemmill-Herren, B., Aidoo, K., Kwapong, P., Martins, D., Kinuthia, W., Gikungu, M., Eardley, C. (2014) Priorities for research and development in the management of pollination services for agriculture in Africa. J. Polit. Econ., 12, 40-51.

Gikungu, M., Wittmann, D., Irungu, D. and Kraemer, M. (2011) Bee diversity along a forest regeneration gradient in Western Kenya. J. Apic. Res., 50, 22-34.

Goulson, D., Sparrow, K.R. (2009) Evidence for competition between honeybees and bumblebees; effects on bumblebee worker size. J. Insect Conserv., 13, 177-181.

Graham, M.D., Ochieng, T. (2017) Uptake and performance of farm-based measures for reducing crop raiding by elephants Loxodonta africana among smallholder farms in Laikipia District, Kenya, Oryx, 42, 76-82.

Hagler, J.R., Mueller, S., Teuber, L.R., Machtley, S.A., Van Deynze, A. (2011) Foraging range of honey bees, Apis mellifera, in alfalfa seed production fields. J. Insect Sci. 11 (144), 1-12.

Hall, M.(2018) Blue and yellow vane traps differ in their sampling effectiveness for wild bees in both open and wooded habitats. Agric. For. Entomol., https://doi. org/10.1111/afe.12281.

Herbertsson, L., Lindström, S., Rundlöf, M. (2016) Competition between managed honeybees and wild bumblebees depends on landscape context. Basic Appl. Ecol., 17, 609-616.

Hoare, R. (2012) Lessons from 15 years of human-elephant conflict mitigation: Management considerations involving biological, physical and governance issues in Africa. Pachyderm, 51, 60-74.

Karidozo, M., Osborn, F.V. (2015) Community based conflict mitigation trials: Results of field tests of chilli as an elephant deterrent. J. Biodivers. Endanger. Species, 3, 144.

Kasina, J.M., Mburu, J., Kraemer, M. and Holm-Mueller, K. (2009a) Economic benefit of crop pollination by bees: a case of Kakamega small-holder farming in western Kenya. J. Econ. Entomol., 102 , 467-473.

Kasina, M., Kraemer, M., Martius, C. and Wittmann, D. (2009b) Diversity and activity density of bees visiting crop flowers in Kakamega, Western Kenya. J. Apic. Res., 48, 134-139.

King, L.E. (2010) The interaction between the African elephant (Loxodonta africana africana) and the African honey bee (Apis mellifera scutellata) and its potential application as an elephant deterrent. Diss. University of Oxford. 
King, L.E., Lawrence, A., Douglas-Hamilton, I., et al. (2009) Beehive fence deters crop-raiding elephants. Afr. J. Ecol., 47, 131-137.

King, L.E., Douglas-Hamilton, I., Vollrath, F. (2011). Beehive fences as effective deterrents for crop-raiding elephants: field trials in northern Kenya. Afr. J. Ecol., 49, 431-439.

King, L.E., Lala, F., Nzumu, H., et al. (2017) Beehive fences as a multidimensional conflict-mitigation tool for farmers coexisting with elephants. Conserv. Biol., 31, 743-752.

Kioko, J., Muruthi, P., Omondi, P., et al. (2008) The performance of electric fences as elephant barriers in Amboseli, Kenya. South African J. Wildl. Res., 38, 52-58.

Locke, B., Fries, I. (2011) Characteristics of honey bee colonies (Apis mellifera) in Sweden surviving Varroa destructor infestation. Apidologie, 42, 533-542.

Lopezaraiza-Mikel, M.E., Hayes, R.B., Whalley, M.R., et al. (2007) The impact of an alien plant on a native plant-pollinator network: an experimental approach. Ecol. Lett., 10, 539-550.

Manfredo, M.J. (2015) Essays on human-wildlife conflict 10 years after the Durban World Parks Congress: An introduction. Hum. Dimens. Wildl., 20, 285-288.

Martins, D.J. (2004) Foraging patterns of managed honeybees and wild bee species in an arid African environment: ecology, biodiversity and competition. Int. J. Trop. Insect Sci., 24, 105-115.

Memmott, J. (1999) The structure of a plant-pollinator food web. Ecol. Lett., 2 , 276-280.

Moritz, R.F.A., Härtel S., Neumann P. (2005) Global invasions of the western honeybee (Apis mellifera) and the consequences for biodiversity. Ecoscience, 12 (3), 289-301.

Mwakatobe, A., Nyahongo, J., Ntalwila, J., et al. (2014) The impact of crop raiding by wild animals in communities surrounding the Serengeti National Park, Tanzania. Int. J. Biodivers. Conserv., 6, 637-646.

Mwangi, D., Kasina, M., Nderitu, J., Hagen, M., Gikungu, M. and Kraemer, M. (2012) Diversity and abundance of native bees foraging on hedgerow plants in the Kakamega farmlands, western Kenya. J. Apic. Res., 51, 298-305.

Nair, R.P., Jayson, E.A. (2016) Effectiveness of beehive fences to deter crop raiding elephants in Kerala, India. Int. Res. J. Nat. Appl. Sci., 3, 14-19.

Ngama, S., Korte, L., Bindelle, J., et al. (2016) How bees deter elephants: Beehive trials with forest elephants (Loxodonta africana cyclotis) in Gabon. PLoS One, 11, e0155690.

Njoroge, G.N., Gemmill, B., Bussmann, R., Newton, L.E. and Ngumi, V.M. (2010) Diversity and efficiency of wild pollinators of watermelon (Citrullus lanatus (Thunb.) Mansf.) at Yatta (Kenya). J. Appl. Hortic., 12, 35-41.

Nyhus, P.J. (2016) Human-wildlife conflict and coexistence. Annu. Rev. Environ. Resour., 41, 143-171.
Okello, M.M., D’Amour, D.E. (2008) Agricultural expansion within Kimana electric fences and implications for natural resource conservation around Amboseli National Park, Kenya. J. Arid Environ., 72, 2179-2192.

Osborn, F. V. (2002) Capsicum oleoresin as an elephant repellent: Field trials in the communal lands of Zimbabwe. J. Wildl. Manag., 66, 674.

Paini, D. (2004) Impact of the introduced honey bee (Apis mellifera) (Hymenoptera: Apidae) on native bees: a review. Austral Ecol., 29, 399-407.

Paini, D., Roberts, J. (2005) Commercial honey bees (Apis mellifera) reduce the fecundity of an Australian native bee (Hylaeus alcyoneus). Biol. Conserv., 123, 103112.

Paterson, P.D. (2016) The Tropical Agriculturalist: Beekeeping, Oxford: Macmillan Education.

Pittiglio, C., Skidmore, A.K., van Gils, H.A.M.J., et al. (2014) Smallholder farms as stepping stone corridors for crop-raiding elephant in northern Tanzania: Integration of Bayesian expert system and network simulator. Ambio, 43, 149-161.

Redpath, S.M., Young, J., Evely, A., et al. (2013) Understanding and managing conservation conflicts. Trends Ecol. Evol., 28, 100-109.

Roubik, D., Wolda, H. (2001) Do competing honey bees matter? Dynamics and abundance of native bees before and after honey bee invasion. Popul. Ecol., 43 , 53-62.

Roulston, T.H., Smith, S.A., Brewster, A.L. (2007) A Comparison of Pan Trap and Intensive Net Sampling Techniques for Documenting a Bee (Hymenoptera: Apiformes) Fauna. J. Kansas Entomol. Soc., 80, 179-181.

Russo, L., Debarros, N., Yang, S., et al. (2013) Supporting crop pollinators with floral resources: Network-based phenological matching. Ecol. Evol., 3, 3125-3140.

Russo, L., Memmott, J., Montoya, D., et al. (2014) Patterns of introduced species interactions affect multiple aspects of network structure in plant-pollinator communities. Ecology, 95, 2953-2963.

Russo, L., Park, M., Gibbs, J., et al. (2015) The challenge of accurately documenting bee species richness in agroecosystems: Bee diversity in eastern apple orchards. Ecol. Evol., 5, 3531-3540.

Shavit, O., Dafni, A., Ne'eman, G. (2009) Competition between honeybees (Apis mellifera) and native solitary bees in the Mediterranean region of Israel-Implications for conservation. Israel Journal of Plant Sciences, 57 (3), 171-183.

Sitati, N.W., Walpole, M.J. (2006) Assessing farm-based measures for mitigating human-elephant conflict in Transmara District, Kenya. Oryx, 40, 279.

Thomson, D. (2004) Competitive interactions between the invasive European honey bee and native bumble bees. Ecology, 85, 458-470.

Tuell, J.K., Isaacs, R. (2009) Elevated pan traps to monitor bees in flowering crop canopies. Entomol. Exp. Appl. 131 (1), 93-98. 